\title{
La residencia como un requisito de elegibilidad electoral
}

\section{Manuel González Oropeza*}

* Magistrado de la Sala Superior del Tribunal Electoral del Poder Judicial de la Federación.

D. R. (c) 2012. Universidad Nacional Autónoma de México-Instituto de Investigaciones Jurídicas. 
El artículo 55, fracción III, de la Constitución Política de los Estados Unidos Mexicanos prescribe que para ser diputado se debe cubrir, entre otros, el requisito consistente en ser originario del Estado en que se haga la elección o vecino de él con residencia efectiva de más de seis meses anteriores a la fecha de ella. De la misma manera, para poder figurar en las listas de las circunscripciones electorales plurinominales como candidato a diputado de representación proporcional, se requiere ser originario de alguna de las entidades federativas que comprenda la circunscripción en la que se realice la elección, o vecino de ella con residencia efectiva de más de seis meses anteriores a la fecha en que la misma se celebre.

Por su parte, el artículo 82, fracción III, de la misma Constitución precisa que para ser presidente de la República se requiere, entre otros requisitos, haber residido en el país durante todo el año anterior al día de la elección y que la ausencia del país hasta por treinta días, no interrumpe la residencia. Igualmente, el artículo 116, fracción I, establece que sólo podrá ser gobernador constitucional de un estado un ciudadano mexicano por nacimiento y nativo de él, o con residencia efectiva no menor de cinco años inmediatamente anteriores al día de la elección.

Conforme con lo anterior, el artículo 122, base segunda, fracción I, segundo párrafo, de la citada Constitución prescribe que para ser jefe de Gobierno del Distrito Federal deberán reunirse los requisitos que establezca el Estatuto de Gobierno, entre los que deberán estar: ser ciudadano mexicano por nacimiento en pleno goce de sus derechos con una residencia efectiva de tres años inmediatamente anteriores al día de la elección si es originario del Distrito Federal o de cinco años ininterrumpidos para los nacidos en otra entidad; tener cuando menos treinta años cumplidos al día de la elección y no haber desempeñado anteriormente el cargo de jefe de Gobierno del Distrito Federal con cualquier carácter. La residencia no se interrumpe por el desempeño de cargos públicos de la Federación en otro ámbito territorial.

La residencia es pues un requisito de elegibilidad permanente en los cargos de elección popular. "Residencia" es definida como la acción de residir ${ }^{1} \mathrm{y}$ en una segunda y tercera acepción se define como población o sitio en que se reside y como casa o edificio en que se vive. La Aca-

\footnotetext{
1 Moliner, María, Diccionario de uso del español, Madrid, Gredos, 2006, p. 938.
} 
demia de la Lengua opina en forma similar. " "Residir" tiene el sentido de "vivir habitualmente en un sitio", 3 es decir "habitar", estar establecido en un lugar. ${ }^{4}$ En el español usual en México, "habitar" significa que alguien vive en un lugar; ${ }^{5}$ por su parte, Moliner sostiene que esta palabra tiene el sentido de "estar habitualmente y, particularmente, dormir, en un sitio que se expresa... Vivir habitualmente en cierto país o región". ${ }^{6}$

Por otra parte, la vecindad es un requisito equivalente a la residencia; "vecino" tiene el sentido de habitante de cierta población; en el español usual en México, un "vecino" es alguien que habita en el mismo pueblo o barrio, en la misma localidad, en la misma cuadra o edificio que uno, es decir, es alguien que está próximo a nosotros, alrededor de nosotros. La "vecindad" es la cualidad de ser vecino, el estado o situación de ser vecinas dos o más personas, pueblos o barrios.

De lo anterior se sigue que la Constitución prescribe como un requisito para ser diputado federal el consistente en ser originario del Estado en que se haga la elección o habitante de él, habiendo vivido de manera efectiva en él más de seis meses anteriores a la fecha de ella. Conforme con lo anterior, pareciera que la expresión "con residencia efectiva de más de seis meses anteriores a la fecha en que la misma se celebre", contenida en el segundo párrafo del artículo 55 constitucional, tiene como sujeto a "vecino de él"; ${ }^{7}$ entonces, el requisito constitucional consistiría en ser originario del Estado en que se haga la elección o habitante o residente efectivo de dicho Estado por más de seis meses anteriores a la fecha de ella.

Derivado de lo anterior, se puede entender que el término "efectivo" se emplea en el sentido de "auténtico", "real y verdadero, en oposición

2 Real Academia Española, Diccionario de la Lengua Española, Madrid, 1992, p. 1781.

3 Moliner, María, Diccionario de uso..., cit., p. 938.

4 Real Academia Española, Diccionario de la..., cit., p. 1781.

5 Lara, Luis Fernando, Diccionario del español usual en México, México, El Colegio de México, 2006, p. 476.

6 Moliner, María, Diccionario de uso..., cit., p. 1448.

7 Aún en el caso de la elección de diputados de representación proporcional, la expresión se refiere a "el" Estado del que se sea originario o en el que se resida, el cual debe estar comprendido en la circunscripción plurinominal respecto de la cual se integre la lista de candidatos de la que se forme parte.

8 Moliner, María, Diccionario de uso..., cit., p. 1056. 
a lo quimérico, dudoso o nominal". ${ }^{9}$ En otras palabras, el simple hecho de tener una habitación en una población (vecino) no es suficiente, sino que se debe vivir real y verdaderamente en el lugar por al menos seis meses antes de la elección.

En el ámbito jurídico, se ha sostenido que en la configuración de la residencia de una persona el elemento fáctico es el más importante, pues se toman en cuenta únicamente los hechos y su especificidad se refiere a la temporalidad. ${ }^{10}$ Lo sobresaliente de lo fáctico estriba en que en la configuración del domicilio (en tanto que atributo de la personalidad) confluyen dos elementos, uno objetivo (la residencia por un tiempo determinado en un lugar dado) y otro subjetivo (la intención de permanencia en dicho lugar). Para que alguien se considere residente no es necesaria la manifestación de la intención de permanencia, basta con vivir habitualmente en un determinado lugar. Así, la noción de residencia es meramente descriptiva de una situación de hecho.

En este sentido, lo requerido por la norma constitucional no entraña sino la constatación de una situación de hecho: que alguien viva realmente en un determinado lugar por un tiempo determinado.

En su momento, la Sala de Segunda Instancia del Tribunal Federal Electoral se pronunció relevantemente en torno al tema de la residencia, al sostener que ésta implica elementos de fijeza y permanencia que consisten en mantener casa, familia e intereses en una comunidad social determinada. El criterio ha resultado por demás orientador de las decisiones del Tribunal Electoral del Poder Judicial de la Federación y a la letra dice: ${ }^{11}$

Vecindad y Residencia. Elementos Que deben ACREDitarse para teNER POR CUMPLIDOS LOS REQUISITOS DE ELEGIBILIDAD. La vecindad y la residencia no se prueban sólo con la existencia de domicilio, ya que también se deben acreditar el tiempo y la efectividad de las mismas, toda vez que el concepto de vecindad implica elementos de fijeza y permanencia que consisten en mantener casa, familia e intereses en una comunidad social determinada. Es decir, para estimar que se han acreditado jurídica-

9 Real Academia Española, Diccionario de la..., cit., p. 791.

10 Cfr. Trigueros, Laura, "Residencia", Enciclopedia Jurídica Mexicana, México, Porrúa-UNAM, 2004, p. 267.

11 Memoria 1994, t. II, p. 744. 
mente los requisitos de vecindad y residencia exigidos por la Constitución Política de los Estados Unidos Mexicanos, no basta con tener inmuebles en propiedad en un lugar específico, sino habitarlos de manera ininterrumpida y permanente.

SD-II-RIN-118/94 y Acumulados. Partido de la Revolución Democrática, Partido del Frente Cardenista de Reconstrucción Nacional y Partido Acción Nacional. 21-IX-94. Unanimidad de votos.

La Sala Superior del Tribunal Electoral del Poder Judicial de la Federación, por su parte, ha abordado en diversas ocasiones el tema. En el caso SUP-JRC-024/2000, la controversia planteada consistió en determinar si entre los requisitos que debían reunir los aspirantes para integrar un ayuntamiento en el estado de Nuevo León, a través de una elección, estaba el de que fueran residentes del municipio donde se ubicara ese ayuntamiento.

En la sentencia se hizo una lectura del artículo 36, fracción V, de la Constitución Política de los Estados Unidos Mexicanos y se concluyó que el sentido de dicho precepto consiste en que, el integrante de un ayuntamiento debe residir en el municipio administrado por el propio órgano colegiado, por lo tanto, el ciudadano, que en calidad de candidato, aspire a ocupar un cargo en un ayuntamiento, a través de una elección, debe residir precisamente en el municipio administrado por el propio ayuntamiento.

El sentido dado al texto interpretado corresponde con la concepción del municipio como una comunidad natural y permanente de familias que viven en un mismo lugar, relacionadas unas con otras para el cumplimiento en común de todos los fines de la vida que trascienden inmediatamente a su esfera privada. Incluso, en sus orígenes, sostiene la sentencia, las familias que integraban el municipio estaban más o menos emparentadas y por ello se sostuvo que, después de la familia, que representa la célula social por excelencia, en orden ascendente seguía la comunidad municipal, como grupo social.

El destacado papel del municipio, como segundo grupo social de importancia después de la familia, se encuentra implícitamente reconocido en los principales lineamientos de su regulación, que es posible advertir de la lectura del artículo 115 constitucional, del cual destacan las siguientes bases: 
1) El municipio libre es la base de la división territorial y de la organización política y administrativa de los estados miembros de la federación.

2) El municipio es gobernado por un ayuntamiento de elección popular directa y no habrá ninguna autoridad intermedia entre éste y el gobierno del estado.

3) El municipio tiene personalidad jurídica y manejará su presupuesto conforme con lo que disponga la ley.

4) El municipio administra libremente su Hacienda.

En lo atinente al municipio como sustento de una división territorial, el territorio municipal constituye la superficie terrestre en donde el orden jurídico propio de la entidad municipal impera de manera exclusiva, marca los límites del municipio y es el espacio en el que operan sus órganos de gobierno. En dicho sitio se asienta la comunidad humana que lo integra.

Respecto de los ámbitos político y administrativo, el municipio es el ámbito de gobierno más inmediato y básico de la estructura política del Estado mexicano. Por tanto, si el precepto citado prescribe que el municipio es administrado por un ayuntamiento de elección popular directa, así como que el municipio manejará su presupuesto y administrará libremente su Hacienda, es claro que las personas que se encarguen de llevar a cabo las actividades indicadas deben ser, en principio, los integrantes del propio municipio, pues esas actividades son inherentes al grupo humano asentado en el territorio municipal, conforme al precepto de referencia.

Por otra parte, la contigüidad de domicilios, de habitaciones, de lugares en los que se vive, tiende a generar (o crea condiciones para que sea más probable que se produzca) entre quienes viven próximos los unos a los otros en un determinado territorio (vecinos) lazos de solidaridad social, de aquí la importancia de la vecindad. Si la proximidad material o la contigüidad de viviendas es premisa indispensable para que pueda producirse la convivencia vecinal en el municipio, es claro que la vecindad de los individuos en dicha porción territorial es factor fundamental que se toma en cuenta para aspectos importantes de la vida municipal, como es, entre otros, el gobierno del municipio.

Los gobernantes del municipio, por ser vecinos de éste, forman parte de la comunidad municipal, cuyos integrantes se encuentran plena- 
mente identificados por compartir las mismas finalidades u objetivos generales. Entonces, bajo esta concepción resulta muy natural, que los cargos para integrar el ayuntamiento de un municipio sean ocupados por ciudadanos que residan en el municipio de que se trate, puesto que si se toma en cuenta que el municipio está integrado por una agrupación humana, en la que el elemento primordial es la vecindad, los individuos residentes en esa porción territorial son quienes tienen pleno conocimiento de las necesidades y problemas de la comunidad a la que pertenecen y a ellos puedan recurrir de manera más inmediata los demás vecinos. Por ende, esos residentes son los que deben gobernar el municipio, es decir, deben gobernarse a sí mismos y a sus vecinos.

En la sentencia reseñada se precisa que entre el derecho de votar (voto activo) y el derecho de ser votado (voto pasivo) hay una correlación. La residencia constituye uno de los elementos que establecen ese vínculo. Por cuanto hace al derecho de ser votado (voto pasivo), por ejemplo el artículo 47, fracción III, de la Constitución Política del Estado de Nuevo León prevé que para ser diputado se requiere ser vecino del estado, con residencia no menor de cinco años inmediatos anteriores a la fecha de la elección. Asimismo, el artículo 82, fracción I, del citado ordenamiento dispone que para ser gobernador se requiere ser ciudadano mexicano por nacimiento, nativo del estado o con vecindad en el estado, no menor de cinco años inmediatos anteriores al día de la elección.

Por cuanto hace al derecho de votar (voto activo) debe tomarse en cuenta que el artículo 5o. de la Ley Electoral del Estado de Nuevo León establece que los ciudadanos neoleoneses ejercerán el derecho al voto activo en la casilla electoral correspondiente a su domicilio. Asimismo, el artículo 37, fracción II, del citado ordenamiento determina que los ciudadanos neoleoneses tienen como obligación la de votar en las elecciones populares en el distrito y sección que les corresponda. Por su parte, el artículo 148, fracción IV, del cuerpo de leyes en cita, señala que los electores deberán solicitar su inscripción en la oficina del Registro Estatal de Electores que corresponda a su domicilio, para lo que deberán presentar constancia de residencia, consistente en un recibo personal de servicio público o una carta de residencia expedida por las autoridades municipales.

Lo anterior condujo a que la Sala Superior estimara en la sentencia reseñada, que por regla general, los ciudadanos sólo pueden ejercer 
el derecho de voto, precisamente en la circunscripción territorial en que tengan su residencia. En contrapartida, ya se vio que uno de los requisitos que deben reunir los titulares de ciertos cargos de elección es el de la residencia. Esto se traduce en que, en la medida de lo posible, el gobernante debe provenir del mismo núcleo habitacional o vecinal al que pertenezcan los electores. De esta manera, si no es concebible que determinados electores puedan ejercer el sufragio en un lugar diferente al que residen, con relación al voto pasivo se tenderá a que el gobernante surja de la comunidad de electores que serán gobernados por aquél. Aun cuando con relación a un determinado órgano de gobierno (gobernador) cuya función tendrá efectos en una más amplia extensión territorial, la ley prevé otras alternativas (el ser nativo del estado de Nuevo León) lo fundamental es que el requisito de la residencia se conserve en el ordenamiento constitucional local y por tanto, es más acorde al actual sistema electoral, la interpretación normativa que tenga en cuenta esa correlación entre el voto activo y el voto pasivo, que una que la soslaye.

Así, no obstante que para algunos cargos de elección popular se prevean alternativas al requisito de la residencia (la oriundez, por ejemplo), tal circunstancia no provoca la disminución de la importancia del requisito de la residencia, puesto que, por un lado, a fin de cuentas se reconoce que debe existir un vínculo entre el gobernante y sus electores y, por otro lado, es explicable que se prevean alternativas con relación a la ocupación de cargos dentro de órganos (como son la Cámara de Diputados y la Cámara de Senadores) cuya función no solamente va a operar dentro de una concreta región, sino que esa función tendrá efectos en todo el territorio nacional.

Finalmente, en la sentencia se justifica la decisión bajo el argumento de que si para las elecciones federales, tratándose de grupos más o menos dispersos en áreas ocasionalmente más amplias, se exige como requisito de elegibilidad, entre otros, la residencia por cierto tiempo en el lugar de la elección, con mayor razón debe satisfacerse el requisito de residencia con relación a los municipios, los cuales, están integrados por una comunidad unida por razones de vecindad, con las particularidades que arriba se detallaron ampliamente.

Un caso de notoria relevancia fue el SUP-JRC-170/2001, mejor conocido como el caso del "Rey del tomate". Andrés Bermúdez Viramontes participó en las elecciones municipales de ese año en Zacatecas, específicamente para integrar, como presidente municipal, el 
ayuntamiento de Jerez. No obstante haber obtenido la mayor cantidad de votos el día de la jornada electoral, Andrés Bermúdez Viramontes fue declarado inelegible por la Sala Superior en razón de no haber cumplido con el requisito exigido de la residencia. Este ciudadano mexicano es un claro ejemplo de lo que cotidianamente sucede con muchos paisanos.

Don Andrés, originario de Jerez, Zacatecas, emigró desde muy joven a los Estados Unidos de América, en donde estableció su residencia, su empresa (dedicada al cultivo y cosecha de tomates) y su vida familiar, a grado tal que en determinado momento, adquirió la nacionalidad estadounidense, aunque posteriormente recobró la mexicana. En 2001, Bermúdez Viramontes se presentó como candidato a presidente municipal del citado municipio y obtuvo la mayoría de los votos; sin embargo, la entrega de su constancia de mayoría fue impugnada a partir del argumento de que don Andrés no satisfacía el requisito de la residencia, pues había declarado públicamente a la prensa que su lugar de trabajo era Sacramento, California, en Estados Unidos de América, donde se ubicaban sus empresas y su familia: su esposa, tres hijos ciudadanos estadounidenses, ocho hermanos y veinte sobrinos, y que por tanto, su residencia formal y de empleo era en el vecino país del norte.

La Sala Superior sostuvo que tenía razón el impugnante, en lo sustancial, respecto a tales aseveraciones, pues en los autos del expediente existían elementos que se consideraron suficientes para arribar a la conclusión de que Andrés Bermúdez Viramontes no tenía residencia efectiva e ininterrumpida en el municipio de Jerez, Zacatecas, durante todo el año inmediato anterior a la fecha de la elección. En la ejecutoria correspondiente, se sostuvo que el requisito de elegibilidad que se analizó se cumplía cuando se satisfacían los siguientes elementos:

a) Vecindad en el municipio en el cual se aspiraba al cargo de presidente municipal. La vecindad, de acuerdo con el criterio orientador de la Sala de Segunda Instancia del Tribunal Federal Electoral antes citado, implica elementos de fijeza y permanencia que consisten en mantener casa, familia e intereses en una comunidad social determinada. Los elementos que, conforme al criterio orientador, constituyen la vecindad obedecen al hecho de que ésta es la unión o conjunto de habitantes en un solo lugar, lo que da origen a un sentimiento de solidaridad o de unión entre sus miembros 
y donde realizan las actividades cotidianas de su vida, de manera que se le caracteriza por la permanencia y el arraigo, revelados por el hecho de tener un lugar para su habitación, su familia y sus intereses.

b) Residencia efectiva, es decir, que sea real, no ficticia y con el ánimo de permanencia.

c) Residencia ininterrumpida, lo cual significa que después de haber establecido la residencia en un lugar determinado, ésta no la haya cambiado a otro sitio, aunque sea temporalmente.

d) Que esa residencia sea por lo menos durante el año inmediato anterior a la fecha de la elección.

La Sala Superior sostuvo (con base en el precedente del SUPJRC-024/2000 aunque sin citarlo) que tal requisito tiene su razón de ser en la necesidad de que los municipios sean gobernados por quienes tengan conocimiento de la problemática que se vive en el seno de esa comunidad, que haya adquirido la solidaridad con el grupo social necesaria para velar por los intereses del mismo, en cuanto se siente parte de él.

En el expediente se encontró evidencia suficiente para sostener que Andrés Bermúdez Viramontes había tenido su domicilio, desde hace muchos años, en Sacramento (California) y se consideró en la sentencia que los medios aportados por don Andrés para probar su residencia en Jerez eran insuficientes para destruir la presunción de que había residido en el mismo lugar en el que se habían ubicado su domicilio, sus empresas y su familia.

En la sentencia se afirmó que el elemento determinante en la conformación del domicilio, es la residencia. Ésta constituye un elemento objetivo, pues se traduce en el hecho de la ubicación física de una persona, al que se agrega el elemento de la habitualidad, para designar el lugar donde constante o comúnmente se le encuentra. La residencia efectiva supone habitar un lugar y permanecer en él. Conforme a la definición aceptada internacionalmente sobre el domicilio, cuando alguien afirma de manera libre y espontánea que su domicilio está ubicado en lugar determinado, esto implica que ahí mismo tiene su residencia y que ésta es habitual, esto es, constante o permanente. Puesto que Andrés Bermúdez Viramontes había afirmado libre y espontáneamente que su domicilio estaba en Sacramento y que éste lo había seguido siendo durante el año anterior a la elección, y en tal lo- 
calidad mantenía la sede de su familia y de sus empresas, la Sala Superior declaró inelegible a dicha persona en razón de haber incumplido el requisito de la residencia.

En forma congruente con lo anterior, es relevante citar el voto particular del magistrado Mauro Miguel Reyes Zapata en la sentencia SUP-JRC-130/2002. En su voto disidente el referido juzgador sostiene que el concepto "residencia efectiva" implica la noción de arraigo en un conglomerado ubicado en un territorio determinado, en atención a elementos objetivamente comprobables y referidos, siempre, a la concreta situación, comportamiento y circunstancias de la persona. La residencia efectiva debe evidenciar que entre el individuo y una determinada colectividad social establecida en cierto territorio se han creado lazos capaces de expresar una auténtica integración. En otras palabras, si la vida de una persona es percibida como parte de la realidad cotidiana en el entorno en el que se produce, porque dicha persona vive, tiene intereses y vínculos con la comunidad de cierto lugar, puede afirmarse que la residencia habitual de esa persona se encuentra en ese lugar.

Además de la relación de una persona con un determinado territorio, el concepto de residencia efectiva encierra también un aspecto sociológico, por identificar el centro de la vida de cada persona, en atención a las circunstancias específicas que acreditan su permanencia de forma continuada en determinado lugar, por la existencia de vínculos e intereses personales, de familia o sociales.

En conclusión, por residencia efectiva debe entenderse el lugar donde la persona se ha establecido de manera habitual y constante, de manera que ha creado un vínculo sociológico por tener ahí sus intereses. Por tanto, para acreditar la residencia efectiva de una persona es indispensable demostrar esa situación de hecho, que revele que en determinado sitio la persona que se dice residente tiene su centro de vida habitual, por los nexos que lo vinculan a la comunidad y por los intereses personales que tenga.

Tal concepción de la residencia efectiva tiene sustento, incluso, en la concepción sociológica e histórica del municipio. Éste es visto no sólo como la organización política y administrativa en la que se sustenta la estructura global del Estado mexicano, sino también como la congregación natural y permanente de grupos familiares, formada sobre la base de una identidad cultural común, de un alto sentido de solidaridad, así como de los vínculos territoriales ancestrales, rasgos 
que caracterizan el estamento municipal y por supuesto, los que permiten determinar a los sujetos que forman parte de él y que, por tanto, se les puede atribuir el status de residentes. ${ }^{12}$

De este modo, si la residencia efectiva tiene que ver con cuestiones y actividades cotidianas que demuestran el arraigo continuado y habitual de una persona, es claro que esa relación de nexos que se crean entre la persona y la comunidad permite que el residente conozca las necesidades, los deseos, las preocupaciones, los intereses familiares y la exigencia de los problemas de la comunidad, entre otros.

Esta íntima relación que existe entre el concepto de municipio y la idea de residencia efectiva se ve tutelado además en la fracción $\mathrm{V}$ del artículo 36 de la Constitución Política de los Estados Unidos Mexicanos, al fijar como obligación de los ciudadanos, entre otras, desempeñar los cargos concejiles del municipio donde resida.

Por otra parte, en la ejecutoria del caso SUP-JRC- 083/2002 (también ponencia del magistrado Reyes Zapata), se afirmó que los elementos integrantes de los conceptos "residencia" y "vecindad", como son el lugar, el tiempo prolongado e ininterrumpido y las relaciones jurídicas sociales entre los integrantes de una comunidad, hacen difícil la demostración de los referidos conceptos.

La residencia que se exige como requisito de elegibilidad implica el contacto prolongado e ininterrumpido que una persona tiene con un determinado lugar, comúnmente, porque vive en él. En cambio, la vecindad, exigida también como requisito de elegibilidad, se refiere a la permanencia que debe tener una persona en un determinado lugar, en el que habite junto con su familia, mantenga sus intereses, conviva con los miembros de ese lugar, conozca los problemas que aquejan a la comunidad y se sienta unido a ella, para velar por los intereses de ella y resolver los problemas que se presenten.

Por lo que implica cada uno de los términos referidos, la sentencia concluyó que es muy difícil que exista una prueba contundente para demostrar la residencia y vecindad de una persona. A esta difícil circunstancia debe agregarse que por regla general, en las legislaciones no se regula la manera de preconstituir una prueba para la demostración de la residencia y vecindad, con relación a la elegibilidad de candidatos a cargos de elección popular.

12 El magistrado Mauro Miguel Reyes Zapata fue el ponente de la sentencia del caso SUP-JRC-024/2000. 
Así, en el precedente citado se fijó el precedente de que para tener por acreditados los requisitos de elegibilidad mencionados ("vecindad" y "residencia"), se debe tomar en cuenta el cúmulo de elementos probatorios que presenten los interesados, con el fin de demostrar que han tenido contacto prolongado con un determinado lugar y que en ese lugar habitan de manera permanente junto con su familia, que ahí se tienen asentados sus intereses y que son parte de la comunidad de ese lugar, a la que los une un sentimiento de solidaridad, porque sólo a través de dichos elementos es como las autoridades pueden verificar que las personas son residentes y vecinos de un determinado lugar.

A partir de este precedente, el tema abordado por la Sala Superior consistió, fundamentalmente, en la prueba de la "vecindad" y de la "residencia" como requisitos de elegibilidad y su problemática técnica. En la sentencia del caso SUP-JRC-197/2002, por ejemplo, se afirmó que tanto la residencia como la vecindad, por su propia naturaleza de continuidad, durante lapsos largos, presentan un alto grado de dificultad para acreditarse, con las características que se suelen exigir por la ley, especialmente cuando no existen mecanismos para preconstituir una prueba de esos hechos, como por ejemplo, el registro municipal; ante tal situación se necesita recurrir ordinariamente a la prueba indiciaria mediante la apreciación de elementos indirectos, revisados detalladamente con gran flexibilidad, para establecer su alcance con apoyo en las reglas de la lógica y las máximas de la experiencia.

En dicha sentencia se mantuvo el criterio de que en los casos en que se impugna el resultado de la calificación de una elección y se invoca como causa de pedir la inelegibilidad del candidato electo, con base en la aseveración de que no satisface el requisito de residencia o vecindad en el lugar de la elección por el tiempo y condiciones determinados legalmente, sin que la ley aplicable exija expresamente su acreditación durante el procedimiento de registro de candidatos, la carga de la prueba corresponde al partido postulante o al propio candidato, en virtud de que las reglas esenciales para determinarla, se traducen, fundamentalmente, en que recae en quien afirma y no en quien niega; sin embargo, existen casos donde la negativa debe demostrarse, como en el supuesto en que envuelva una afirmación tácita o cuando se pretenda desconocer una presunción legal que exista a favor de su contraparte.

Sin embargo, la sentencia del caso SUP-JRC-203/2002 es por demás relevante, pues en ella se operó un cambio de criterio en torno a la carga de la prueba en la materia. En la ejecutoria se precisó que la 
Sala Superior había sostenido que en todos los casos en que se controvirtiera la residencia de un candidato, como requisito de elegibilidad, correspondía a éste o al partido político que lo postulaba la carga de acreditar la satisfacción de esa exigencia, por tratarse de un hecho positivo y no a quien rechazara ese hecho, por ser una simple negación. ${ }^{13}$

Sin embargo, después de realizar un nuevo estudio con mayor detenimiento y ponderación de los elementos normativos con los que se regula el tema, se advirtió que una mejor interpretación sistemática y funcional del conjunto de reglas y principios aludidos, conducía de manera sencilla y natural, a la determinación de que deben distinguirse dos situaciones diferentes.

La primera se presenta con relación al registro de los candidatos para contender en una elección, cuando la legislación aplicable exige al partido postulante o al candidato la comprobación de la residencia en los términos legales correspondientes, como elemento sine qua non para otorgar el registro de la candidatura, en que el otorgamiento o negación de dicho registro se reclama en un medio de impugnación.

En esta hipótesis debe subsistir el criterio sostenido en diversas resoluciones, porque si la ley impone directamente al partido postulante o al candidato la acreditación del citado requisito de elegibilidad ante la autoridad administrativa electoral, sin que exista ninguna actuación precedente sobre esa cuestión, está fuera de duda que el cumplimiento de esa obligación se traduce o convierte en una carga probatoria, dentro del proceso que se llegue a suscitar con motivo de ese hecho, ya sea por acción deducida por el partido postulante o el candidato contra la negación del registro, o por la promoción del partido político o ciudadano legitimado, para reclamar la concesión del registro, ya que en el primer supuesto, la obligación administrativa electoral se traduce procesalmente en la carga de acreditar que sí fueron aportados los elementos necesarios ante la autoridad electoral, para acreditar la residencia en los términos de la ley, así como en la carga de exponer la argumentación necesaria para desvirtuar las consideraciones desestimatorias en que se sustentó el órgano electoral, mientras que en la segunda hipótesis, cuando se reclama el otorgamiento del registro, la impugnación produce el efecto inmediato de que la resolución electoral permanezca subjudice, de modo que no se

13 Se citaron, de manera ejemplificativa, los casos SUP-JRC-160/2001, SUPJRC-323/2001 y SUP-JDC-102/2001, aunque se aclaró que en el caso SUP-JRC-264/2001 se apuntó hacia diversos derroteros. 
puede invocar la fuerza de su autoridad en el proceso jurisdiccional, lo que lleva a que dentro del objeto del proceso impugnativo sea necesario determinar si el candidato o su partido cumplieron con la carga de demostrar la residencia ante la autoridad electoral responsable, por lo que el onus probandi debe soportarse, en principio, por la propia autoridad que tuvo por justificado el requisito de elegibilidad, así como por la parte tercera interesada, en su calidad de coadyuvante de la autoridad para la conservación del acto de autoridad combatido en sus términos, en tanto que el impugnante del registro sólo tendrá a su cargo el cuestionamiento racional de las consideraciones que fundan la resolución reclamada.

La segunda situación se presenta cuando la concesión del registro al candidato no es objeto de ninguna impugnación, por lo que el aspirante al puesto de elección popular queda en aptitud de participar en la contienda, mediante los actos de campaña electoral y de los demás que se relacionen con su posición y llega hasta la jornada electoral en la que obtiene el triunfo en los comicios, por favorecerle la mayoría relativa de la votación, y esto trae como consecuencia la declaración explícita o implícita de su elegibilidad en el acto de calificación de la elección y la entrega de las constancias conducentes, en donde el acto objeto de la impugnación consiste precisamente en la proclamación. En este caso procede una variación del criterio sustentado con anterioridad.

En primer lugar, la obligación legal de acreditar el cumplimiento del requisito de residencia, impuesta al partido político o al propio candidato cuyo registro aquél solicita, ya se consideró cumplida por la autoridad electoral competente, por lo que la acreditación de la residencia ya no se encuentra amparada en las constancias aportadas por el partido político o el candidato, sino en la resolución administrativa electoral en que se concedió el registro, en la que se tuvo por satisfecho el requisito.

Lo anterior le proporciona a la satisfacción del requisito de la residencia una fuerza jurídica de importante consideración, que le da firmeza durante el desarrollo del proceso electoral en que se emite, y la protege con la garantía de la presunción de validez que corresponde a la generalidad de los actos administrativos, lo que impone la producción total de los efectos de la resolución, mientras no se demuestre plenamente lo contrario de su contenido, ante la autoridad competente para su revisión y mediante el procedimiento legal previsto. 
Más aún, la decisión en que se tiene por acreditada la residencia del candidato por la autoridad electoral constituye también una garantía de la autenticidad de las elecciones, como todos los actos de la etapa de preparación del proceso electoral, por lo que su fuerza y valor jurídicos se incrementa con la sucesión de los actos electorales subsecuentes, en los que se involucra cada vez más a los principales destinatarios que son los integrantes de la ciudadanía, esto es, la determinación del registro se va fortaleciendo con los actos posteriores vinculados a ella, especialmente con la celebración de la jornada electoral, en donde se emite el sufragio en ejercicio del poder soberano de los ciudadanos, que es la función sustantiva y de mayor importancia en los comicios, toda vez que el registro de los candidatos y las actuaciones consecuentes se enlazan y mezclan estrechamente entre sí y con la emisión de la voluntad de los electores, de tal modo que el surgimiento de cada uno aumenta la base de apoyo y fuerza jurídica de los demás, a tal grado, que la modificación de los efectos de cualquiera de ellos, decretado con posterioridad a la jornada electoral, afecta en importante medida a los restantes, dentro de la inercia surgida en el desarrollo del proceso electoral, y dentro de ese mecanismo, al contenido de la voluntad expresada en la emisión del voto.

Todo lo anterior genera una presunción de validez de especial fuerza y entidad y por lo tanto, requiere para su desestimación la existencia de prueba plena del hecho contrario al que se soporta en ella, que en el caso implique la demostración total de que el candidato residió en lugar distinto al que exige la ley, ya sea durante todo el plazo exigido o en alguna parte del mismo, o simplemente que en alguno de estos lapsos se constate que no residió en ningún punto del área territorial de que se trate, por lo que, de no darse esta situación, debe subsistir la validez del acto que tuvo por acreditada la residencia.

La desestimación de la residencia se puede producir, ex oficio, en el acto de calificación de la elección, si la autoridad que la lleva a cabo cuenta con los elementos suficientes para alcanzar la plena convicción de que no está satisfecho el requisito mencionado de residencia, o bien, en el proceso impugnativo que se promueva contra la declaración del candidato victorioso, en donde la pretensión del actor consista en el desconocimiento del valor de fuerte presunción de que siga cubierta la resolución en que se declaró justificada la residencia; en cuyo caso, el onus probandi sobre los hechos de la demanda pesa precisamente sobre el actor, y si no cumple con ella, ni en autos quedan acreditados 
los hechos con otros medios probatorios que recabe la autoridad, en ejercicio de su poder para allegarse pruebas, la consecuencia lógica y jurídica consiste en dictar una resolución desestimatoria en la que se confirme el acto reclamado.

Considero que lo más benéfico es que la inelegibilidad por falta de residencia o de cualquier otro requisito similar pueda hacerse valer sólo hasta antes de la jornada electoral para evitar que maliciosamente se espere atacar al candidato triunfador para anular su elección, lo cual es castigar al electorado que lo eligió.

La Sala Superior consideró que una nueva posición representa ventajas importantes sobre la anterior, en tanto que resulta más acorde con la naturaleza y finalidades de los procesos electorales, en cuanto que:

a) Tiende, en lo posible, a la conservación de los actos electorales válidamente celebrados.

b) Evita la imposición de una doble carga procedimental sobre los partidos y sus candidatos respecto del mismo hecho consistente en acreditar la residencia para la obtención del registro, sin que éste sea objeto de impugnación, y volverlo a hacer a pesar de eso, ante la simple negación del impugnante de la calificación de la elección, que tuvo oportunidad de formular su oposición con anterioridad y no lo hizo.

c) Pone coto a la posible malicia con que se puedan conducir algunos partidos políticos, cuando consideren o tengan conocimiento de que un candidato al que se concede el registro no reúne la residencia como requisito de elegibilidad que se le tiene por demostrada en la resolución, en el sentido de abstenerse intencionalmente de presentar un medio de impugnación en contra del registro y reservar esa posibilidad, con ánimo de especulación, para el caso de que dicho candidato sea favorecido por la voluntad popular en la elección, ya que esa conducta es contraria a la función de representantes de los intereses difusos de la ciudadanía que se ha reconocido a los partidos políticos, porque en lugar de velar por la autenticidad, transparencia y validez de los actos de preparación del proceso, en beneficio de todos los electores, estarían priorizando un interés propio, posiblemente en fraude a la ley; asimismo, se impide que la voluntad del electorado se vea disminuida y en alguna forma frustrada con la presentación como elegibles de los candidatos por los 
que emite su voto y la determinación posterior de que no reúnen los requisitos para dicha elegibilidad, pues es innegable que aunque la votación se emite por los dos integrantes de una fórmula, ésta se presentó y debe surtir sus efectos como una alternativa, en la que en primer lugar se encuentra el candidato propietario, y sólo en forma secundaria se piensa en el suplente al momento de sufragar, esto es, la voluntad soberana del pueblo va dirigida, preponderantemente, a que el cargo sea ocupado por el propietario.

Todas las circunstancias precisadas resultan más acordes con los mejores fines de la ley y de su interpretación jurídica, en donde no es admisible la apertura de espacios para la actuación maliciosa de los gobernados o para la desviación de los fines y la merma de los valores que se encuentran en juego.

La Sala Superior afirmó que, las reglas esenciales contenidas en los principios generales de derecho para determinar a quién corresponde la carga de la prueba en un procedimiento, se traducen fundamentalmente en que tal carga recae en quien afirma y no en quien niega, sin embargo, existen casos en que la negativa debe demostrarse, como en el supuesto en que envuelva una afirmación tácita o cuando pretenda desconocer una presunción que exista a favor de su contraparte; otra regla consiste en que cada uno de los colitigantes debe asumir la carga de la prueba de los hechos constitutivos de sus respectivas pretensiones.

Así, cuando se trate de desvirtuar la presunción de validez de la que está revestido el acto administrativo de registro de un candidato, respecto a su residencia, la regla aplicable es que quien pretenda destruirla, le pesa el gravamen procesal de acreditar lo contrario.

Otro precedente relevante es el sentado en la sentencia del SUPJRC-045/2007, ${ }^{14}$ también relacionado con la legislación de Zacatecas. En la sentencia sometida a la revisión constitucional electoral de la Sala Superior, el tribunal señalado como autoridad responsable adujo que la exhibición de una constancia de residencia expedida por un secretario de gobierno municipal era una exigencia insalvable, porque el requisito de elegibilidad, consistente en la residencia efectiva en el municipio de que se trate, durante el periodo que exige la ley, no podía demostrarse por otros medios.

14 Esta sentencia fue aprobada por mayoría de seis votos respecto del tema que se analiza. El magistrado Eloy Fuentes Cerda disintió del sentido mayoritario de la Sala Superior. 
En la sentencia de la Sala Superior se sostuvo que, al contrario de lo afirmado por el tribunal responsable, para tener por demostrado el requisito consistente en la residencia efectiva en el municipio de que se trate, durante el lapso exigido anterior a la fecha de la elección, la constancia de residencia que expidiera el secretario de gobierno municipal es un documento previsto en la ley como una forma de preconstituir la prueba de ese hecho, en beneficio del ciudadano, pero tal situación no impedía que el requisito mencionado pudiera demostrarse con otros medios de igual o mayor valor convictivo cuando se encontraran dificultades serias para obtener la constancia señalada directamente por la ley. Se concluyó, pues, que la constancia de residencia no constituye un elemento ad solemnitatem, sino ad probationem.

En la sentencia se precisó que la residencia es un hecho complejo, conformado por la continuidad, permanencia y arraigo de una persona durante lapsos prolongados en un determinado lugar, y por tanto, presenta un alto grado de dificultad su acreditación absoluta (como ya se había afirmado en los precedentes aquí referidos), con las características que se suelen exigir por la ley, especialmente porque se trata de hechos continuos en el tiempo y en el espacio, por lo que resulta prácticamente imposible que a través de personas, instrumentos o mecanismos se puedan acreditar directa y absolutamente, y en consecuencia, cobra vigencia el principio de que a mayor dificultad probatoria, menor exigencia de pruebas. Se dijo que de no atender a este principio, se podría llegar a situaciones absurdas, en las que se exigiera, por ejemplo, que a un testigo o fedatario le conste que durante las veinticuatro horas del día, durante todos los días de los meses que integren algún plazo previsto en la ley, la persona de que se trate mantuvo su residencia efectiva en un lugar determinado.

En consecuencia, para la demostración de hechos como el que nos ocupa, es necesario acudir a las reglas de la inferencia, tales como aquella que deriva del aforismo latino probatis extremis, media censentur probata, cuyo significado es que cuando se prueban los extremos, se presume que impera la misma situación en el intermedio, salvo prueba en contrario.

Debido a la dificultad probatoria que implica demostrar el hecho complejo de la residencia, el legislador suele prever mecanismos para preconstituir pruebas que puedan ser útiles para ese efecto; por ejemplo, se refiere en la sentencia que el artículo 74, fracción XVI, de la Ley Orgánica del Municipio del Estado de Zacatecas, regulaba el registro 
municipal, respecto del cual se facultaba al presidente municipal para formar y organizar el catastro y padrón municipal, cuidando de que se inscriban en este último todos los vecinos, expresando su nombre, edad, estado civil, nacionalidad, residencia, domicilio, propiedades, profesión, actividad productiva o trabajo de que subsistan, si son jefes de familia, en su caso, el número y género de las personas que la forman. En otros casos, se establecían ciertos procedimientos administrativos ante las autoridades municipales, con la finalidad de que se les facilite a los interesados la prueba del requisito en comento.

Para la Sala Superior era claro que esa especie de instituciones fueron creadas a favor de los ciudadanos, a efecto de proporcionarles una opción, entre tantas otras que puedan existir en la realidad, para obtener la prueba eficaz y accesible, que puede ser expedida por algún funcionario de su propia comunidad.

Por lo anterior, sostuvo la Sala Superior, se entendía por qué el legislador del Estado de Zacatecas había establecido en el artículo 124.1 de la ley electoral, que a la solicitud de registro de candidaturas se debía acompañar, entre otros documentos, constancia de residencia expedida por el secretario de gobierno municipal, pues es claro que estimó que una vez cumplido lo señalado en el artículo 74, fracción XVI, de la Ley Orgánica del Municipio, los funcionarios municipales estarían en aptitud real de emitir certificaciones y constancias relacionadas con las circunstancias propias de cada uno de los habitantes del lugar.

Sin embargo, en los hechos, la Sala Superior consideró que se evidenciaba la falta de operatividad real de los mecanismos señalados, entre otras cosas, porque en muchos lugares no se cumplen los preceptos que exigen a las autoridades locales la organización y actualización del registro de domicilio y vecindad y esto impide que las constancias que ordinariamente se expiden, tengan el soporte documental que les dote de un alto grado de fuerza convictita y que los procedimientos indagatorios sean de carácter empírico, conforme al leal saber y entender de quienes los ordenan y los ejecutan.

Esto, según la ejecutoria de la Sala, podía conducir a la imposibilidad o extrema dificultad para la obtención de dicha constancia, en ciertos casos, a pesar de que el interesado cuente con elementos que proporcionen igual o mayor grado probatorio respecto de los hechos que serían materia de la constancia. En estos casos, lo que pretendió ser una facilidad para los gobernados se torna en dificultad conside- 
rable, por lo que puede abandonar válidamente ese procedimiento y recurrir a otros distintos.

Con relación a los candidatos, el requisito sustantivo de elegibilidad, cuya prueba se exigía para el otorgamiento del registro era el hecho de la residencia, y la ley recurría al medio que ordinariamente se puede obtener con mayor facilidad por los partidos políticos o los candidatos, que es la constancia municipal, pero la Sala consideró que esto no vetaba o prohibía que en los casos de gran dificultad para su obtención se pudieran presentar otros elementos, es decir, la Sala Superior consideró que el texto normativo no prescribía que únicamente, sola o exclusivamente se pudiera probar el requisito con la susodicha constancia, por lo cual, en atención al principio de libertad para la aportación de pruebas en beneficio de un interés, mientras no estén prohibidas o sean contrarias a la moral o al derecho, los interesados podían presentar otros elementos, con apoyo además en el principio de que los gobernados pueden hacer todo lo que no les esté prohibido, y la autoridad electoral deberá valorarlos de acuerdo con las reglas de la lógica y las máximas de experiencia.

Ciertamente, a falta de la constancia de residencia que expidiera el secretario de gobierno municipal, por la dificultad en su obtención, debían tomarse en cuenta los elementos que presentaran los interesados con el fin de demostrar que habían tenido contacto prolongado con un determinado lugar y que en ese lugar habitaban de manera permanente, generalmente junto con su familia, que ahí tenían asentados sus intereses y que eran parte solidaria de la comunidad, porque a través de dichos elementos se podía verificar que las personas eran residentes y/o vecinos de un determinado lugar.

En circunstancias como la descrita, la Sala Superior precisó en la sentencia que la experiencia demuestra que para acreditar la residencia efectiva en un lugar y tiempo determinados, los ciudadanos suelen aportar elementos tales como la credencial para votar con fotografía, recibos de pago de servicios, tales como el telefónico, de energía eléctrica, de derechos de consumo de agua; recibos de pago de impuestos, constancias de antecedentes penales, de concesiones para prestar distintos servicios, constancias relacionadas con centros de trabajo, contratos de arrendamiento, documentos expedidos por autoridades locales, certificados de estudio, actas del registro civil y declaraciones testimoniales, entre otras, exponiendo argumentos objetivos y racio- 
nales que satisfagan la exigencia de un alto grado de confirmación del hecho que se pretende acreditar.

El caso del SUP-JRC-045/2007 se abordó a partir del criterio sustentado en el SUP-JRC-203/2002, puesto que se impugnaba la decisión del tribunal electoral zacatecano consistente en revocar la decisión de la autoridad administrativa electoral de la entidad de otorgar el registro de candidato a una persona que demostró cumplir con el requisito de la residencia mediante medios diversos a la constancia expedida por el secretario de gobierno del municipio correspondiente. Es decir, ya se había generado una presunción de validez de especial fuerza y entidad, y por lo tanto su desvirtuación requería la existencia de prueba plena del hecho contrario, lo que implicaba la demostración total de que el candidato residió en lugar distinto al que exigía la ley, ya sea durante todo el plazo exigido o en alguna parte del mismo, o simplemente que en alguno de estos lapsos no había residido en ningún punto del área territorial del municipio.

En la ejecutoria se consideró que la constancia de residencia expedida por el secretario de gobierno municipal constituye un mero elemento de comprobación del requisito de elegibilidad consistente en ser vecino del municipio que corresponda, con residencia efectiva durante el periodo de seis meses inmediato anterior a la fecha de la elección previsto en el artículo 118 de la Constitución zacatecana y 15.1 de la Ley Electoral.

Como simple instrumento de demostración que es, se estimó que la referida constancia no era un requisito que la ley exigiera para que se configure el hecho consistente en la residencia efectiva en un lugar determinado durante el lapso que marca la ley (caso en el cual se estaría ante un elemento ad solemnitatem). Es decir, la residencia es un hecho objetivo, cuya configuración no depende de la existencia de la documental en cuestión y en realidad, la constancia expedida por el secretario de gobierno municipal sólo constituye un documento que sirve como medio de prueba para demostrar que el hecho objetivo de la residencia ocurrió en un lugar y periodo determinados.

Por tanto, el requisito de elegibilidad relativo a la residencia efectiva en el municipio de que se trate es susceptible de demostración con medios de prueba distintos a la constancia señalada, los cuales pueden tener la misma o mayor fuerza de convicción sobre ese hecho.

La Sala Superior afirmó que asumir la posición contraria llevaría a admitir que en relación con el registro de candidatos a los cargos de 
elección popular de los ayuntamientos de Zacatecas, en una situación extrema, en la que, por ejemplo, el plazo para registrar planillas de candidatos estuviera cercano a su expiración y algún partido político interesado en registrar candidatos no pudiera obtener la constancia de residencia del secretario de gobierno municipal, porque éste estuviera ausente y no fuera posible suplirlo conforme a la ley aplicable, el partido se viera privado injustamente del derecho a registrar candidatos, por no contar con la referida constancia, a pesar de que contara con medios diversos de prueba con los que el hecho objetivo de la residencia pudiera ser demostrado ante la autoridad administrativa electoral.

Además, se abundó en la ejecutoria, si bien la constancia de residencia expedida por el secretario de gobierno municipal en el estado de Zacatecas es apta para acreditar el requisito de la residencia, su contenido puede ser desvirtuado por pruebas mediante las que se establezca la falta de autenticidad del documento o la falta de veracidad de los hechos a los que se refiera. Es decir, la existencia o inexistencia del hecho objetivo consistente en la residencia efectiva en un lugar y tiempo determinados no depende, en manera alguna, de la expedición de la constancia por el secretario de gobierno municipal, a grado tal que aun en el extremo en el que se exhiba una constancia en la que se afirme que alguien residió en un lugar y tiempo determinados, se puede acreditar mediante pruebas distintas que esa afirmación es falsa.

Por otra parte, la Sala Superior estimó que la exigencia de la residencia como garantía de que el candidato conoce la problemática, necesidades y prioridades de la comunidad a la que pretende gobernar, había sido exigida de manera extrema porque se consideraba la única forma posible de conseguir ese objetivo, entre otros aspectos, por el poco desarrollo de los medios de comunicación y de transporte; sin embargo, en virtud del gran avance de dichos medios, se ha facilitado enormemente el conocimiento de la situación determinada de un lugar, a tal grado que en ocasiones es posible tener datos precisos y confiables de acontecimientos de un municipio o una región, en forma casi simultánea a su realización aun estando lejos del lugar e incluso obtenerlos antes que los propios habitantes, y de igual manera, el tiempo de desplazamiento entre puntos geográficos se ha reducido considerablemente.

La Sala Superior consideró que esa flexibilización respecto del requisito de residencia como elemento para demostrar la vinculación apuntada con la comunidad, se puede advertir de la interpretación 
funcional de la legislación de Zacatecas, en materia electoral. Ciertamente, en el artículo 12 de la Constitución local se establece que para el ejercicio de los derechos y prerrogativas en materia electoral, se admite la residencia binacional y simultánea en el extranjero y en el territorio del estado cuando se cumplan ciertos requisitos que la propia norma contempla. Por su parte, el artículo 5o., fracción XXXIV, de la Ley Electoral del Estado de Zacatecas define residencia binacional como la condición que asume una persona para poseer simultáneamente domicilio propio en el extranjero y domicilio y vecindad en el territorio del estado, manteniendo en él, casa, familia e intereses.

En la exposición de motivos de la reforma al artículo 12 de la Constitución mencionado, se estableció que en ese estado el fenómeno de la migración se ha incrementado en gran medida en los últimos años, "pero que ese efecto se compensa con el surgimiento de numerosas comunidades filiales, permitiendo a los zacatecanos reproducir binacionalmente y de manera simultánea su sentido de comunidad, residencia, pertenencia, membresía, participación social, política y cultural". Asimismo, se señaló que los anteriores requisitos legales para poder participar en la vida política del Estado resultaban obsoletos e incompatibles con la realidad descrita, tal como la "residencia efectiva".

Por lo anterior y de acuerdo a una interpretación conforme con el principio de igualdad establecido en el artículo 1o. de la Constitución Política de los Estados Unidos Mexicanos, la Sala Superior del Tribunal Electoral del Poder Judicial de la Federación precisó que esa posibilidad de doble residencia tiene que hacerse extensiva para las personas que desean contender para algún cargo de elección popular pero que por razones de trabajo o estudio, entre otras, constantemente se ausentan o apartan del lugar en el cual tienen su residencia habitual, pero dentro del territorio nacional o incluso dentro del mismo estado, sin que tal situación implique una ruptura o alejamiento total, ya sea porque mantienen lazos familiares, de trabajo, negocios o propiedades o cuestiones similares, pues la misma razón para conceder ese beneficio a las personas que trabajan en otro país debe aplicarse para quienes radican dentro del territorio nacional. En ese contexto, se decidió que no era indispensable la exhibición de la constancia de residencia expedida por la autoridad municipal. ${ }^{15}$

15 También relacionado con la legislación zacatecana, el precedente del SUPJRC-179-2004, en el que se planteó el litigio en torno a la residencia efectiva de la candidata que había obtenido más votos para ocupar la gubernatura del estado. 
Esto ha sido una descripción sucinta de algunos de los principales criterios judiciales en torno al cumplimiento del requisito de residencia en materia electoral. El estudio de precedentes extranjeros, como los casos Melnychenko-Ucrania (núm. 17707/02) y Py v. France (núm. 66289/01) de la Corte Europea de Derechos Humanos, así como el caso Maksym v Board of Election Commissioners of the City of Chicago (1-11-0033, 2011) de la Suprema Corte del estado de Illinois en Estados Unidos (caso de Rahm Emanuel), permite afirmar que los criterios asumidos por el órgano jurisdiccional federal coinciden en términos generales con los de otros juzgadores, lo cual no indica otra cosa más que cierta comunión en lo básico. 